\title{
Tobacco policy research comes of age
}

Tobacco control policies have been adopted since the very beginning of the anti-tobacco movement. ${ }^{1}$ In 1965 , one year after release of the US Surgeon General's first report on smoking and health, Congress passed legislation to require health warnings on cigarette packs. Two years later, the Federal Communications Commission applied its Fairness Doctrine to cigarette advertising in the broadcast media, requiring television and radio stations to run anti-smoking public service announcements (PSAs) as long as cigarette commercials remained on the air. In 1969 , Congress banned cigarette advertising on television and radio. In the mid-1970s, states began to adopt clean indoor air laws.

Even though these policies were adopted in those early years of the anti-tobacco campaign, policy interventions were fairly low on the tobacco control agenda. Instead public education, smoking cessation programmes, and school prevention programmes were the mainstays of tobacco control efforts. It became increasingly clear, however, that these approaches, as important as they are, were not enough to reduce smoking prevalence to the low levels desired. As a result, policies intended to discourage smoking and to protect non-smokers' health gradually moved up on the agenda of tobacco control advocates and policy makers. Tobacco taxes, clean indoor air policies, restrictions on tobacco advertising and promotion, reducing minors' access to tobacco, and tobacco product regulation are now considered essential features of a comprehensive tobacco control strategy. ${ }^{2-4}$

Research on the effectiveness of tobacco control policies evolved even more slowly than the policies themselves. With few exceptions - for example, a study by Warner of the impact of the Fairness Doctrine PSAs ${ }^{5}$ - very little research was conducted to measure the impact of the policies adopted in the 1960s and 1970s. Even after tobacco control policies began to receive more serious attention and were adopted with increasing frequency, they continued to be ignored for many years by most of the research community. One notable effort to study and to stimulate research on tobacco policies came from the Institute for the Study of Smoking Behavior and Policy at Harvard University's John F Kennedy School of Government. The Institute, which sponsored seminars and published monographs on tobacco policy issues - for example, one on cigarette taxation ${ }^{6}$ - was formed in 1984 and dissolved in 1990.

Despite its slow start, the status of tobacco policy research has turned around completely during the past decade. And Tobacco Control, with support from the Robert Wood Johnson Foundation, is poised to assume an expanded role in the dissemination of policy research findings.

\section{Historical underpinnings}

How has tobacco policy research, in a period of only 10 years, moved from poverty to prominence? The story begins with the now-defunct National Coordinating Committee on Tobacco-Related Research. Established in the early 1980s by the American Cancer Society (ACS), the committee's purpose was to provide a mechanism to review and assess scientific progress in the field of smoking and health, to share information on current research activities and plans of participating agencies, and to recommend priority needs for future research to its constituencies and to the scientific community as a whole. The committee's membership included representatives of federal agencies and voluntary health organisations involved in tobacco-related research. Chaired by former US Surgeon General Jesse L Steinfeld and staffed by ACS, the committee met once or twice a year.

In the mid-1980s, the National Cancer Institute (NCI) and the National Coordinating Committee developed a taxonomy of tobacco-related research "to enable potential coordination of and cooperation among research efforts as well as to identify gaps in these efforts". "The taxonomy categorised research into seven primary areas: (a) product (studies focusing on "modification and component analysis of tobacco from the plant stage through the cigarette stage and on methods for measuring doses"); (b) physical effects of voluntary/involuntary tobacco use; (c) behavioural factors in voluntary/involuntary tobacco use; (d) social effects of voluntary/involuntary tobacco use; (e) individual interventions; (f) social and policy interventions; and (g) technology transfer (studies focusing on "creating an awareness of and interest in knowledge and use of information concerning tobacco-related issues").?

The taxonomy was used to classify 767 tobacco-related research projects funded in 1985 by federal agencies. The classification was based on information in abstracts of the research projects. The abstracts came from the Public Health Service's CRISP database (Computer Retrieval of Information on Scientific Projects) and from the federal Office on Smoking and Health's Directory of on-going research in smoking and health (oral communication, Marianne Haenline Alciati, NCI, 6 February 1995), which was published biennially to $1986 .^{8}$ The distribution of these 767 projects among the taxonomy's seven primary categories was: product, $72(9.3 \%)$; physical effects, 354 $(46.2 \%)$; behavioural factors, $148(19.3 \%)$; social effects, $4(0.5 \%)$; individual interventions, $186(24.3 \%)$; social and policy interventions, $3(0.4 \%)$; and technology transfer, 0 . As expected, health-effects research received the lion's share of funding, whereas policy research was barely on the map.

The three projects in the social and policy interventions category included one in the subcategory "economic incentives" and two in the subcategory "smoking in public places". There were no projects with a primary classification in the remaining subcategories: "advertising/labeling", "controlled substance/licensing", "regulation of component content", and "export/import policies"?

Although this taxonomic exercise included only federally funded research projects, the research funding allocations of non-governmental funding agencies were presumed to be similar. Another survey of tobacco-related research, conducted at about the same time, included research funded by governmental and non-governmental agencies. ${ }^{9}$ It yielded similar findings. This survey classified 683 research projects related to tobacco and health that were active in fiscal years 1984 or 1985 into 31 subject categories. Most of the projects fell into one of the following areas: health effects of smoking, 219 (32.1\%); compounds/contaminants in tobacco or tobacco smoke, $134(19.6 \%)$; cessation and relapse, $99(14.5 \%)$; psycho- 
behavioural factors, $65(9.5 \%)$; and community and school interventions, $60(8.8 \%)$.

None of the 31 categories was related specifically to policy interventions, but three policy-oriented projects $(0.4 \%$ of the total) were included in the "other" category. Two of these projects focused on price policy, and the third addressed clean indoor air laws. All three were funded by federal agencies. ${ }^{9}$ Thus, this survey found no policy-related research projects funded by private (nongovernmental) agencies, suggesting that the private sector was doing no better than government in funding policy research.

\section{Defining the agenda}

- In response to the National Coordinating Committee's findings, the director of the NCI's Smoking, Tobacco, and Cancer Program, the late Joseph W Cullen, commissioned a study of the current state of tobacco policy research and development at the local, state, and national levels. The study was performed by John Pinney, a former director of the Office on Smoking and Health and executive director of Harvard's Institute for the Study of Smoking Behavior and Policy.

In his report, ${ }^{10}$ Pinney concluded that:

there is a serious lack of empirical evidence to guide the design of what might be termed the "next generation" of policies and to assess the impact of the first generation. For example, there is a very limited body of research on the impact of workplace smoking restrictions on smoking behavior, nonsmoker satisfaction, or air quality; there are no published studies that examine the effects of a municipal smoking ordinance on attitudes and behavior; there are no studies that measure the economic impact of public, restaurant, or workplace restrictions; there are no published studies which assess the impact of recent excise tax increases on teenage smoking behavior.

Pinney identified several factors responsible for the paucity of research on tobacco policies: (a) lack of funding; (b) lack of defined professional and career incentives for conducting such research; (c) lack of awareness by potential researchers of the need for and value of such research; and (d) lack of organised demand for research from policy advocates. He noted that "established sources of tobacco research support - foundations, the voluntary health agencies, and the federal government - have not evidenced or communicated a strong interest in and commitment to supporting such research."10

To address these problems, Pinney recommended the creation of a national network of researchers, policy makers, and advocates to support tobacco control policy research and development. The network would establish working groups for several specific policy areas, whose initial responsibility would be "to define the basic library for their area, identify major research gaps, and assess the state of policy development in that area". In addition, Pinney recommended that a joint funding mechanism be established to support research "targeted to fill gaps identified by the working groups on a priority basis". $\mathrm{He}$ estimated that $\$ 200000-300000$ per year would be needed "for a period of several years to accommodate the most pressing needs". ${ }^{10}$

At a meeting in February 1990, the National Coordinating Committee discussed Pinney's report and recommendations. It decided to form an Ad Hoc Task Force on Public Policy Research to develop an implementation plan. ${ }^{11}$ The task force met the following June, and developed an implementation plan that included the appointment of study groups in eight areas of tobacco policy research. ${ }^{12}$ Four months later, the National Coordinating Committee approved the appointment of eight study groups (and their chairpersons) in the following areas: (a) tobacco tax and pricing policy; (b) smoke-free air policy; (c) access to tobacco products; (d) regulation of tobacco products; (e) tobacco marketing and promotion; (f) agriculture and trade; (g) product liability; and (h) insurance and reimbursement. Several federal agencies, along with the American Cancer Society and the American Medical Association, agreed to sponsor meetings of these study groups. ${ }^{13}$

The National Coordinating Committee formed a Subcommittee on Tobacco Policy Research to oversee the work of the study groups. The subcommittee held an organising meeting with the study group chairs in January 1991. The individual study groups then met, and continued to work after their meetings to prepare and refine their reports. During this stage, Michael Pertschuk of the Advocacy Institute provided important leadership. Ultimately the reports were published as a special supplement to Tobacco Control, ${ }^{14}$ which was edited by Drs Simon Chapman and Michele Bloch. A consensus agenda for tobacco policy research was now defined.

\section{Providing the resources}

Now that a research agenda was established, the main need remaining was funding to support that agenda. A breakthrough came when the Robert Wood Johnson Foundation (RWJF) announced the formation of a Tobacco Policy Research and Evaluation Program in 1992. RWJF committed $\$ 5$ million to the programme. In two separate, competitive grant cycles in 1993 and 1994, the Foundation funded a total of 18 research projects. In addition, RWJF has launched a new $\$ 11$ million programme in substance abuse policy research that is seeking proposals related to tobacco as well as alcohol and illicit drugs (written communication, Robert G Hughes, 1 February 1995).

California's Proposition 99 (Prop 99), which increased the state cigarette excise tax from $10 \notin$ to $35 \varnothing$ per pack in 1989 , earmarked $5 \%$ of the new revenues to research on tobacco-related disease. ${ }^{15}$ These funds were used to create a Tobacco-Related Disease Research Program (TRDRP), which awarded $\$ 128$ million in research grants from 1990 to 1994 . According to TRDRP, $\$ 13.7$ million (11\% of total funding) was awarded for grants in "public health/public policy".16 Glantz and Bero, however, reported that the amount of funding allocated for policy research declined from $\$ 6$ million in the first funding cycle $(8 \%$ of total funding) to $\$ 1$ million in the second cycle ( $3 \%$ ) to "less than $\$ 500,000$ " in the third cycle $(1 \%){ }^{17}$

Although the proportion of TRDRP funding allocated to policy research has been relatively small, several important projects have been funded, including research on the economic impact of laws banning smoking in restaurants, ${ }^{18}$ the effects of cigarette advertising on adolescent females, ${ }^{19}$ the impact of Prop 99 and its tax increase on cigarette consumption, ${ }^{20,21}$ political campaign contributions by the tobacco industry ${ }^{22}$, industry submissions to the US Environmental Protection Agency, ${ }^{23}$ and industry-sponsored symposia on environmental tobacco smoke. ${ }^{24}$ TRDRP has committed resources to sponsor a special supplement to Tobacco Control (to be published later this year) devoted to policy research funded by TRDRP.

In response to criticism over the declining support for policy research, TRDRP issued a request for applications (RFA) in October 1993 for projects in the area of "public policy for tobacco control". Two million dollars were set aside for this programme. A new Study Section was established to evaluate the 20 proposals submitted in 
response to the RFA, and the Study Section met in May 1994.

The California legislature, however, diverted funds from the TRDRP budget (for fiscal years 1993-94, 1994-95, and 1995-96) to medical services and tobacco control, preventing funding of the policy research projects approved by TRDRP (written communication, Charles L Gruder, 21 October 1994). Several health groups filed a lawsuit challenging the legality of the funding diversions. ${ }^{25}$ In December 1994, a state superior court judge ruled that the funding diversions were indeed illegal ${ }^{26} ; \mathrm{a}$ month later he ordered the State of California to restore approximately $\$ 128$ million in illegal diversions from the Prop 99 Health Education and Research accounts, ${ }^{27}$ raising hopes that the TRDRP's full budget will be appropriated and that the approved policy research projects will be funded.

A third major funding commitment was made when the NCI issued its own RFA for tobacco policy research in early 1994. The NCI has dedicated approximately $\$ 4$ million to fund proposals submitted in response to this RFA ( $\$ 1$ million per year for four years). Following TRDRP's lead, the NCI established a special Study Section, which met in January 1995 to evaluate the 30 proposals generated by the RFA.

Yet another funding source arose when Canada's International Development Research Centre (IDRC) announced at the Ninth World Conference on Smoking and Health (held in Paris in October 1994) the launch of the International Initiative for Tobacco Policy Research. ${ }^{28}$ This initiative will fund "economic, agricultural, environmental, health, social, and legislative research in support of effective public policy and in support of the development of feasible transition activities for tobacco producers". ${ }^{29}$ Funded jointly by IDRC and Canada's federal Ministry of Health, the programme will have initial resources of $C \$ 2.15$ million. ${ }^{30}$ IDRC anticipates further substantial funding through contributions from other donor organisations (e-mail communication, Anne Phillips, 3 February 1995). Unlike the other funding sources mentioned above, the IDRC initiative will target its funding to research addressing developing countries.

\section{Disseminating the findings}

The policy research circle will be closed when research findings are effectively disseminated and used by advocates and policy makers. I am pleased to announce that the Robert Wood Johnson Foundation has provided a threeyear grant to Tobacco Control to support dissemination of tobacco policy research findings. This grant will allow us to devote more pages of each issue to tobacco policy research. We hereby put out a special call to researchers to encourage them to submit their work in this area to the journal. To highlight our articles on policy research, we will group them together and list them in our table of contents under the heading "Policy forum". In this issue of Tobacco Control, five articles appear in this section.

As the body of policy research grows, it will become increasingly important to synthesise the findings of that research. The Surgeon General's reports have played a valuable role in synthesising the abundant research in many areas of tobacco and health. The 1989 and 1994 reports of the Surgeon General ${ }^{1,31}$ provided substantial coverage of tobacco policy research, and the 1996 report will, in part, return to that subject (oral communication, Michael P Eriksen, 9 February 1995). In addition, the $\mathrm{NCI}$ is planning to publish state-of-the-art monographs on tobacco policy interventions (written communication, Donald R Shopland, 31 January 1995).

\section{Monitoring progress}

As more tobacco policy research is designed, funded, and conducted, and as the findings are published, the remaining challenge is to monitor progress. Which gaps in our research agenda have been filled and which have not? Are the research needs of advocates and policy makers being met? Have changes in the tobacco marketplace created the need for new areas of research?

One area of tobacco policy research that has been particularly neglected pertains to the antecedents of policy adoption. ${ }^{32}$ What factors facilitate or impede the adoption of policies? What is the relative importance of these factors? How effective are various strategies designed to intervene in the policy-making process? Research in this area may help explain, for example, why the US lags so far behind other industrialised countries in some important areas of tobacco control policy (namely, taxation and restrictions on advertising and promotion).

In his report, John Pinney made several specific recommendations for continuing oversight and reevaluation within the national network for tobacco control policy research and development. ${ }^{10}$ For the most part, that oversight and re-evaluation have been lacking. The National Coordinating Committee on Tobacco-Related Research has not met since 1990 . The study groups that laid out the agenda for tobacco policy research ${ }^{14}$ have not re-convened since they finished their reports in 1991.

The various stakeholders and funding agencies involved in tobacco policy research need to create mechanisms to coordinate and evaluate their efforts so that this longawaited research enterprise will accomplish its mission efficiently and effectively. Ideas worth considering are: (a) re-establishing the National Coordinating Committee on Tobacco-Related Research; (b) re-convening the committee's study groups on policy research; (c) periodic meetings of representatives of agencies that fund policy research for the purpose of coordination; (d) periodic conferences and seminars devoted to tobacco policy research; (e) refinement of the tobacco research taxonomy, to be used to measure trends in research over time; and ( $f$ ) as Pinney suggested, ${ }^{10}$ creation and designation of collaborating centres for tobacco policy research.

\section{Editor}

RONALD M DAVIS

David Burns, Simon Chapman, Robert G Hughes, Nancy J Kaufman, and Donald $\mathrm{R}$ Shopland provided helpful comments on an earlier draft of this editorial. 1 US Department of Health and Human Services. Reducing the health General, 1989. Rockville, Maryland: Public . A report of the Surgeon Disease Control, Office on Smoking and Health, 1989. (DHHS Publication No (CDC) 89-8411.)

2 Houston T, ed. Tobacco use : an American crisis. Final conference report and recommendations from America's health community. Chicago: American Medical Association, 1993.

3 US Department of Health and Human Services. Strategies to control tobacco use in the United States : a blueprint for public health action in the 1990's. Bethesda, Maryland: National Institutes of Health, National Cancer Institute, 1991. (NIH Publication No 92-3316.)

4 Institute of Medicine. Growing up tobacco free : preventing nicotine addiction in children and youths. Washington, DC: National Academy Press, 1994.

5 Warner KE. The effects of the anti-smoking campaign on cigarette consumption. Am f Public Health 1977; 67: 645-50.

6 Institute for the Study of Smoking Behavior and Policy. The cigarette excise tax, April 17, 1985. Cambridge, Massachusetts : Harvard University, John F Kennedy School of Government, 1985.

7 Attachment to the Minutes of the 29 August 1987 meeting of the National Coordinating Committee on Tobacco-Related Research.

8 US Department of Health and Human Services. 1984-1985 Directory : ongoing research in smoking and health. Rockville, Maryland: Public Health Service, Centers for Disease Control, Office on Smoking and Health, 1986

9 US Department of Health and Human Services. Smoking and health: a national status report. A report to Congress. Rockville, Maryland: Centers for Disease Control, Office on Smoking and Health, 1986: 267-467. (DHHS Publication No (CDC) 87-8396.)

;

$=$

$=$

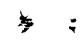

2

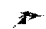

$-$

$-5$

F.

$\$$

5

$\checkmark$

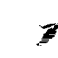

$?$

5

5

$=$

8 
10 Pinney J. Report on a study of tobacco policy research and development (draft). Prepared for the Smoking, Tobacco and Cancer Program, National Cancer Institute. Bethesda, Maryland: Corporate Health Policies Group, Inc, Institute. Bethesda,

11 Minutes of the 23 February 1990 meeting of the National Coordinating Committee on Tobacco-Related Research.

12 Minutes of the 11 June 1990 meeting of the Task Force on Public Policy Research, National Coordinating Committee on Tobacco-Related Research. Committee on 30 October 1990 meeting Control 1992; 1 (suppl): S1-56.
Copman S, Bloch M, eds. Policy Bal DG, Kizer KW, Felton PG, Mozar HN, Niemeyer D. Reducing tobacco consumption in California: Development of a statewide antitobacco use campaign. $7 A M A 1990 ; 264: 1570-4$.

16 Tobacco-Related Disease Research Program. Annual report to the State of California Legislature 1994. Oakland, California: University of California, Office of the President, 1995.

17 Glantz SA, Bero LA. Inappropriate and appropriate selection of 'peers' in grant review. FAMA 1994; 272: 114-6.

$18 \mathrm{Glantz}$ SA, Smith LRA. The effect of ordinances requiring smoke-free Glantz SA, Smith LRA. The effect of ordinances requiring smoke-free

19 Pierce JP, Lee L, Gilpin EA. Smoking initiation by adolescent girls, 1944 through 1988: An association with targeted advertising. F $A M A$ 1994; 271: 608-11.

20 Keeler TE, Hu T-W, Barnett PG, Manning WG. Taxation, regulation, and addiction: a demand function for cigarettes based on time-series evidence. f Health Econ 1993; 12: 1-18.

$21 \mathrm{Hu}$ T-W, Bai J, Keeler TE, Barnett PG, Sung H-Y. The impact of

An innovative learning and leadership opportunity offering 12 week long in-depth courses on tobacco control topics such as: excise tax policies, clean indoor air, media and policy advocacy, tobacco advertising, and youth access to tobacco.

Participants can select two courses per week. Tuition per course is $\$ 250$.

For more information, contact Len C. Stanley

UNC Tobacco Control Training Center

CB\# 7595, Manning Drive

Chapel Hill, NC 27599-7595

Phone 919-966-3711 • Fax 919-966-6125
California Proposition 99, a major anti-smoking law, on cigarette consumption. $\mathcal{f}$ Public Health Policy 1994; 15: 26-36.

22 Glantz SA, Begay ME. Tobacco industry campaign contributions are affecting tobacco control policymaking in California. $\mathcal{f} A M A 1994 ; 272$ : 1176-82.

23 Bero $\mathrm{LA}$, Glantz SA. Tobacco industry response to a risk assessment of environmental tobacco smoke. Tobacco Control 1993; 2: 103-13.

24 Bero IA Galbraith A Rennie D Sponsored symposia on environmental to

25 Skolnick AA. Antitobacco advocates fight 'illegal' diversion of tobacco control money. $\mathcal{F} A M A$ 1994; 271 : 1387-90.

26 Coronado $\mathrm{R}$. State is loser in tobacco tax fight. Sacramento Bee, $1994 \mathrm{Dec}$ $23 ; \mathrm{B} 1, \mathrm{~B} 4$.

27 Skolnick AA. Judge rules diversion of antismoking money illegal, victory for California tobacco program. $\mathcal{F} A M A$ 1995; 273: 610-11.

28 International Development Research Centre. International tobacco policy research: A partnership initiative. Ottawa, Canada: IDRC, 1994.

29 Medhora R, Phillips A, de Savigny D. The economics of tobacco trade: Enabling the transition. Tobacco Control 1994; 3: 295-6.

30 Anon. Canada announces new funding initiative. Tobacco and health-the journal of the 9th World Conference on Tobacco and Health, 1994 Oct 10:

31 US Department of Health and Human Services. Preventing tobacco use among young people. A report of the Surgeon General. Atlanta, Georgia : Public Health Service, Centers for Disease Control and Prevention, Office on Smoking and Health, 1994. (US Government Printing Office No S/N 017-001-00491-0.)

32 Chapman $S$. Upgrading the academic respectability of advocacy studies. Tobacco Control 1992; 1 : 81-3.

July $9-14,1995$ and July $16-21,1995$

The University of North Carolina at Chapel Hill's

\section{Tobacco Control Summer Institute}

UNC-CH Center for Health Promotion/Disease Prevention

CDC's Office on Smoking and Health

2.

